\title{
Moyamoya tipping point: fatal bilateral MCA territory infarction following cocaine abuse
}

\author{
Mark Daniel Unger, ${ }^{1}$ Joseph Georges, ${ }^{2}$ Hamza A Shaikh, ${ }^{2}$ Tapan Kavi ${ }^{3}$
}

'Department of Anatomy, University of New England College of Osteopathic Medicine, Biddeford, Maine, USA

${ }^{2}$ Neurosurgery, Cooper University hospital, Camden, NJ ${ }^{3}$ Department of Neurology and Neurosurgery, Cooper University Hospital, Camden, NJ, USA

Correspondence to

Dr Tapan Kavi,

Kavi-Tapan@Cooperhealth.edu

Accepted 9 December 2017

\section{DESCRIPTION}

An adult Caucasian man with a history of polysubstance abuse was found unresponsive by the nursing staff at his rehabilitation centre and intubated by emergency medical services. On examination, he was stuporous, his eyes did not open to stimulation, his pupils were reactive, localised to pain with bilateral upper extremities and demonstrated triple flexion to noxious stimuli in the bilateral lower extremities. Urine toxicology was positive for cocaine metabolites. A CT scan of the head was performed, which showed possible hypodensities in the bilateral temporal lobes. MRI of the brain was performed to further characterise these hypodensities, and it revealed bilateral middle cerebral artery (MCA)
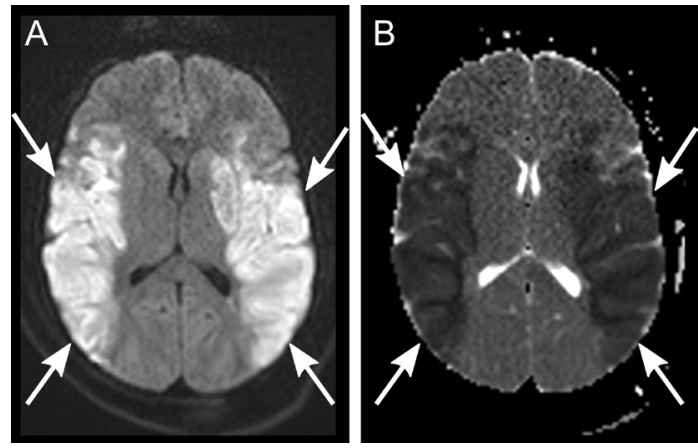

Figure $1 \mathrm{MRI}$ of the brain shows bilateral middle cerebral artery (MCA) territory infarction, and demonstrates bilateral infarction of the MCA territory on (A) diffusion-weighted imaging and (B) apparent diffusion coefficient sequences (arrows).
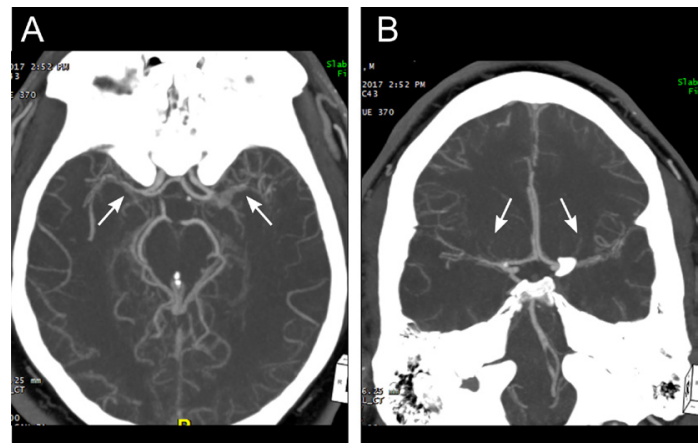

Figure 2 CT angiogram of the head with contrast reveals bilateral middle cerebral artery (MCA) narrowing (arrows) and moyamoya appearance on the left. The left proximal MCA segment (M1) is severely narrowed and hypervascular lenticulostriate vessels are seen on (A) axial and (B) coronal reconstructions. infarction and generalised cerebral oedema (figure 1). CT angiogram of the head at this point was performed, which showed narrowing of both MCAs and possible moyamoya pattern on the left (figure 2). This moyamoya-like vascular change was suggested by narrowing of the left MCA and hypervascular lenticulostriate arteries, likely as a result of chronic changes. An intracranial pressure (ICP) monitor (bolt) was placed, which showed steadily rising pressures. Despite sedative measures, osmotherapy, pharmacological induction of paralysis and maximised treatment for ICP, he continued to develop intractable ICP. A CT scan at this point showed evidence of uncal and tonsillar herniation, and infarcts from compression of the posterior cerebral arteries. After discussion with family, his treatment was transitioned to comfort care and he died shortly after palliative extubation.

Moyamoya represents a chronic, progressive vasculopathy resulting in decreased intracranial blood flow and secondary development of collateral blood supply to perfuse the area of distal ischaemia. ${ }^{1}$ Cocaine-induced cerebral vasospasm has been well-described with there being several case reports and series. ${ }^{2}$ The chronic vascular changes seen in this case differentiate it from the previous reports on strokes related to cerebral vasospasm and cocaine use. Chronic cocaine use can lead to chronic vascular changes, possibly including moyamoya seen in this case. ${ }^{3}$ The underlying mechanism for these observed chronic changes is unknown but may be related to vasculitic changes similar to that seen with methamphetamine use. ${ }^{3}$ While the aetiology of moyamoya associated with demise in this patient remains unknown, this case suggests that chronic cerebrovascular pathology can lower the threshold for acute stroke with subsequent cocaine use, as seen in this case.

\section{Learning points}

- Cocaine use can lead to cerebral vasospasm and ischaemic stroke.

- Chronic cocaine use may represent one factor leading to chronic cerebrovascular change, possibly including moyamoya, which can lower the threshold for ischaemic stroke with subsequent use.

Contributors MDU wrote the manuscript and acquired the data. JG acquired the data and provided critical revision of the manuscript. HAS and TK provided critical revision of the manuscript. 
Competing interests None declared.

Patient consent Not required.

Provenance and peer review Not commissioned; externally peer reviewed.

(C) BMJ Publishing Group Ltd (unless otherwise stated in the text of the article) 2018. All rights reserved. No commercial use is permitted unless otherwise expressly granted.

\section{REFERENCES}

1 Scott RM, Smith ER. Moyamoya disease and moyamoya syndrome. N Eng/ J Med 2009:360:1226-37.

2 Levine SR, Brust JC, Futrell N, et al. A comparative study of the cerebrovascular complications of cocaine: alkaloidal versus hydrochloride-a review. Neurology 1991:41:1173-7.

3 Storen EC, Wijdicks EF, Crum BA, et al. Moyamoya-like vasculopathy from cocaine dependency. AJNR Am J Neuroradiol 2000;21:1008-10.

Copyright 2017 BMJ Publishing Group. All rights reserved. For permission to reuse any of this content visit

http://group.bmj.com/group/rights-licensing/permissions.

BMJ Case Report Fellows may re-use this article for personal use and teaching without any further permission.

Become a Fellow of BMJ Case Reports today and you can:

- Submit as many cases as you like

- Enjoy fast sympathetic peer review and rapid publication of accepted articles

- Access all the published articles

Re-use any of the published material for personal use and teaching without further permission

For information on Institutional Fellowships contact consortiasales@bmjgroup.com

Visit casereports.bmj.com for more articles like this and to become a Fellow 